\title{
Immune responses in yersinia-associated reactive $\operatorname{arthritis}^{1}$
}

\author{
K. AHO, P. AHVONEN, T. JUVAKOSKI, M. KOUSA, M. LEIRISAlo, AND \\ O. LAITINEN
}

From the Central Public Health Laboratory, Helsinki, Finland

There is increasing evidence of a relationship between intestinal infection caused by Yersinia enterocolitica and a subsequent acute non-purulent arthritis.

\section{Features of arthritis}

Yersinia-associated arthritis has the following features:5, 6, 193 (1) It appears typically 1-2 weeks after the infection and subsides gradually within a few weeks or months. (2) Bacterial cultures of synovial fluid and blood are negative. (3) Antibiotic treatment has no distinct effect on its course.

These characteristics of the disease suggest that the arthritis does not result from a direct microbial invasion of the joint but is more probably related to some host response. This type of joint inflammation may appropriately be called reactive. Yersinia arthritis and rheumatic fever share many features, although the mechanisms of the host response presumably are not the same in these diseases. While, in addition to arthritis, a $Y$. enterocolitica infection may be associated with inflammatory complications similar to those seen in group A streptococcal infections, an arthritis very similar to yersinia arthritis may follow certain other infections (Table 1).

Salmonella, Shigella, and Yersinia bacteria all share the so-called enterobacterial-common antigen. ${ }^{202 a}$ Furthermore, it has been speculated that Chlamydiae are degenerated bacteria, possibly enterobacteria, adapted to intracellular parasitism. It is not known if they also posesss this antigen.

\section{Immunogenetics}

If a laboratory-detected abnormality were to be implicated in the occurrence of arthritis in a yersiniainfected patient one would expect it to be: (1) present in arthritis-associated yersinia infection; (2) also present in arthritis associated with salmonella and

${ }^{1}$ This work was supported by the Finnish Medical Research Council and the Sigrid Juselius Foundation, Finland.
Table 1 Inflammatory reactions associated with various infections, showing similarities.

\begin{tabular}{lll}
\hline Infectious agent & $\begin{array}{l}\text { Inflammatory } \\
\text { reaction }\end{array}$ & $\begin{array}{l}\text { Genetic } \\
\text { predisposition }\end{array}$ \\
\hline Group A streptococcus & $\begin{array}{l}\text { Erythema nodosum } \\
\text { Glomerulonephritis }\end{array}$ & $?$ \\
& $\begin{array}{l}\text { Rheumatic fever } \\
\text { Erythema nodosum }\end{array}$ & $?$ \\
Yersinia & Glomerulonephritis? & $?$ \\
& Arthritis & HLA-B27 \\
& Arthritis & associated \\
Salmonella & Arthritis & associated \\
Shigella & HLA-B27 \\
& Arthritis & associated \\
Chlamydia? & & HLA-B27 \\
& & associated \\
\hline
\end{tabular}

shigella infections; (3) missing in patients with uncomplicated yersinia infection; and (4) absent in yersinia infection with nonarticular extraintestinal complications.

The clue that at present seems most promising in this respect is the association between HLA antigen B27 and the reactive arthritis that follows the above enteric bacterial infections. ${ }^{2}$ Among the numerous associations between the histocompatibility antigens and the diseases this one is especially revealing, since the responsible micro-organism is known. This offers additional possibilities for speculation and straight forward experiments to elucidate the role of immune-response (or immune-suppression) genes affecting disease susceptibility.

\section{Cell-mediated antiyersinia and antibacterial immunity}

The following T-cell abnormalities in patients with B27-associated rheumatic diseases have been reported: (1) Reduced responses to a low dose of phytohaemagglutinin in ankylosing spondylitis and RS. ${ }^{122}$ (2) Diminished mixed lymphocyte reaction in patients with ankylosing spondylitis, in their relatives, and in normal individuals with B27. ${ }^{235}$ (3) Lower 
percentage of $\mathrm{T}$-cells in patients with ankylosing spondylitis irrespective of their HLA type. ${ }^{104}$

Such 'non-specific 'abnormalities are also seen in patients with rheumatoid arthritis. Therefore it is difficult to assess the value of these findings.

To investigate more specific immunological abnormalities in patients with yersinia arthritis and other forms of reactive arthritis we tested the transformation of peripheral blood lymphocytes by yersinia antigen and certain other bacterial antigens. Possible differences between responders and nonresponders can be detected most readily by using suboptimal doses of antigen, as exemplified by the work of Greenberg et al. ${ }^{\mathbf{1 4 3}}$ on the in-vitro responsiveness of peripheral blood lymphocytes to streptococcal antigens. Therefore we selected a rather low antigen concentration. The general plan of the study is shown in Table 2. A cell-mediated immune response to the homologous (isolated and identified) antigen could be demonstrated in a considerable proportion of the patients, whereas significant responses were rarely observed to the other antigens.

Patients with yersinia arthritis and patients with yersinia infection but no arthritis (subsequently labelled 'controls') constituted the largest group in which the causative microbe was known. Fig. 1 indicates that using the yersinia antigen, the blastogenic response was very similar in the yersinia arthritis patients and the non-arthritic yersinia controls. Some patients were tested repeatedly for up to six months. Fig. 2 shows that the heightened responses usually declined during the follow-up period both in the patients with yersinia arthritis and the non-arthritic controls. The large group of patients with RS after non-gonococcal urethritis (NGU) seldom showed significant stimulation

Table 2 Plan of study to test transformation of peripheral blood lymphocytes by yersinia and other bacterial antigens in patients with yersinia and other forms of reactive arthritis.

\begin{tabular}{|c|c|c|}
\hline Patients with: & No. & Antigens used \\
\hline \multicolumn{3}{|l|}{ Reactive arthritis } \\
\hline Yersinia & 17 & Yersinia, ${ }^{*}$ Salmonella, ${ }^{*}$ \\
\hline Salmonella & 3 & Shigella, ${ }^{*}$ Group A \\
\hline Shigella & 1 & $\begin{array}{l}\text { streptococci, }{ }^{*} \text { Candida } \\
\text { albicans }\end{array}$ \\
\hline RS after NGU & 41 & \\
\hline Rheumatic fever & 3 & \\
\hline \multicolumn{3}{|l|}{ No reactive arthritis } \\
\hline Yersinia & 11 & \\
\hline Salmonella & 2 & \\
\hline Shigella & 3 & \\
\hline
\end{tabular}

* Whole bacteria $10 \mu \mathrm{g}$ dry weight/ml. RS=Reiter's syndrome. $\mathrm{NGU}=$ non-gonococcal urethritis.
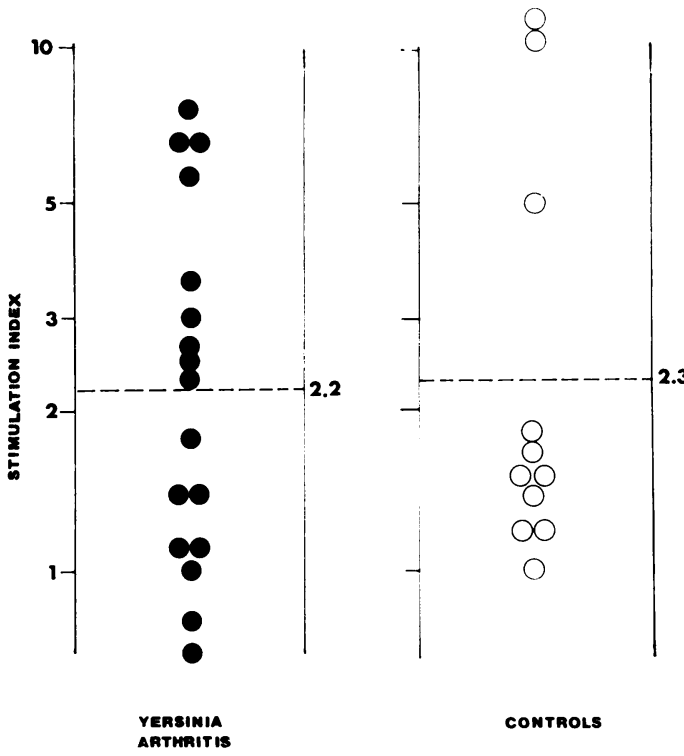

Fig. 1 In-vitro stimulation of peripheral blood lymphocytes from patients with yersinia arthritis and non-arthritic yersinia infected patients ('controls'). Ratio of DPM (by scintillation counting). Cultures stimulated by $10 \mu \mathrm{g}$ dry bacteria to DPM in unstimulated cultures.

with any of the antigens used.* The sera were tested for yersinia agglutinins, but no titres were significantly raised.

There were only a few patients with salmonella or shigella infections. The results obtained in these patients were in agreement with those in patients with yersinia infection.

The reactive arthritis in patients without the HLA-B27 antigen has been of shorter duration and affected fewer joints, and these patients have a lower incidence of sacroiliitis, carditis, and iritis than their HLA-B27-positive counterparts. ${ }^{2} 193$ A possible relationship between the cellular immune responsiveness, severity of the disease, and presence or absence of HLA-B27 was investigated but the available data did not permit any conclusions.

Thus, using small amounts of stimulating antigen, we have shown that some patients with yersinia infection respond with their peripheral blood lymphocytes to yersinia antigen and some do not, but this responsiveness or non-responsiveness is not obviously related to the incidence of arthritis in these patients.

*Chlamydia and $U$. urealyticum (mycoplasma) were not represented in the battery of bacterial antigens-Editor. 


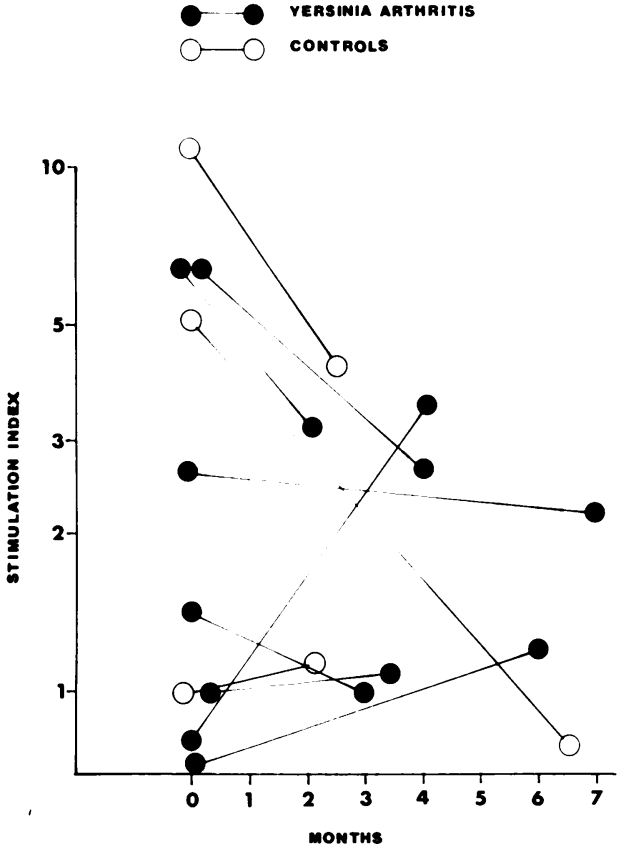

Fig. 2 Evolution of yersinia-induced lymphocyte stimulation index in patients with yersinia arthritis and non-arthritic yersinia controls (see text).

Humoral antiyersinia and antibacterial immunity in reactive arthritis and various rheumatic diseases

To obtain information on the spectrum of humoral antibacterial immunity in various rheumatic diseases of recent onset we examined sera from adult patients with swelling of at least one joint and whose symptoms at the beginning of the survey had lasted for not more than six months. Subsequent diagnoses and numbers of patients were as follows: reactive arthritis 34, Reiter's syndrome 35, definite rheumatoid arthritis 99 , probable rheumatoid arthritis 101 , ankylosing spondylitis 18 , systemic connective tissue disease 9, arthritis of unknown diagnosis 82 , others 64 -a total of 442 patients.

Sera were tested for (1) yersinia agglutinins, (2) salmonella agglutinins, (3) antistreptolysin $\mathrm{O}$ (only from fresh sera), (4) antistaphylolysin, (5) gonococcal complement fixing antibodies, and (6) ornithosis complement fixing antibodies (only from frozen sera). The testing was done twice-once from fresh specimens, and again from deep-frozen sera from age- and sex-matched non-arthritic individuals from the general population (of the same area) who were used as controls.
Yersinia agglutinins were detected in a proportion of patients throughout all the rheumatic diseases tested but occurred more often at entry $(12 \%)$ than on follow-up screening $(5 \%)$. This difference is mainly due to the occurrence of yersinia agglutinins at entry in $21(62 \%)$ patients with reactive arthritis and in $15(18 \%)$ patients with arthritis of unknown diagnosis. (In most of the latter, however, the titres were low and not diagnostic as such.)

Except for yersinia agglutinins, antibacterial antibodies did not occur more often at onset or at follow-up testing. The incidence of antibodies to ornithosis was equal in both arthritic patients and non-rheumatic controls.

The incidence of antibodies of the above-listed specificities was significantly higher in the arthritis patients, regardless of diagnosis, than in the matched controls. Moreover, when antiyersinia antibodies were titrated in the 17 patients with yersinia arthritis and the 11 non-arthritic yersinia-positive controls the average concentration of serum agglutinin was slightly higher in the arthritic patients (geometric mean titre $1: 2940$ ) than in non-arthritic controls (mean titre 1: 1940). This finding is in agreement with previous observations. ${ }^{5}$

\section{Conclusion}

B27 appears to be a marker for an arthritic-type reaction (but not for other inflammatory reactions) to various bacterial antigens, notably yersinia. When trying to characterise the immune responsiveness in arthritic (or spondylitic) patients lymphocytes were found to react to the homologous bacterial antigen in various types of bacterial reactive arthritis. But some arthritis patients did not differ from non-arthritic controls in that respect and, on follow-up examination the lymphocyte response did not decrease consistently. On the other hand, yersinia agglutinins, although found in some patients with any kind of rheumatic disease, were definitely more frequent at the onset of reactive arthritis than at follow-up testing. Antibacterial antibodies (of any kind) were found more often in arthritis patients than in non-arthritic controls. Anti-yersinia agglutinin titres were somewhat higher in yersinia arthritis than in non-arthritic yersinia controls.

\section{General dicusssion}

DR. M. ROSENTHAL: A few years ago it was questioned whether B27 might be associated with circulatory abnormality of the pelvis or sacroiliac region, allowing an unknown agent to get into the circulation without being neutralised by, for instance, the liver. 
Does anybody know anything about this possibility? PROF. M. ZIFF: Professor Aho's data prompt me to mention some of our own. Dr. Alvin Fox, a bacterial chemist, worked in our laboratory last year and isolated a lipoprotein antigen and a lipopolysaccharide antigen from Shigella flexneri as well as a whole homogenate of such bacteria. All these antigens were prepared with the idea of seeing whether B27-positive patients would respond to them differently from controls. We tested about six patients, some with RS, some with ankylosing spondylitis. Like you, we saw stimulation but there was no difference between these individuals and normal controls in the height of stimulation. What is the incidence of arthritis in yersinia-induced diarrhoeal disease?

PROF. AHO: An estimate of this incidence is very difficult to obtain as most cases of diarrhoeal disease due to yersinia infection are mild and go unnoticed. There was, however, one epidemic of yersinia infection affecting 100 people and one of them got RS. Among individuals with serum anti-yersinia antibodies those with arthritis tended to have a higher titre, although barely significantly so.

PROF. A. S. RUSSELL: Because B27 is located within an immune-response gene area we tend to think of immune responses as the answer. I think Professor Aho's data illustrate very effectively, at least in the yersinia area, that immune responses are not relevant. But, as Professor Pearson and Professor
Masi pointed out today, there are many alternative possibilities besides any relationship to immunology, such as Dr. Schwarbs's entirely non-immune model. We ought perhaps to be looking at things like clearance of peptidoglycans from macrophages or by macrophages in relation to B27 rather than straightforward simple immune responses. In this regard, I gathered from Professor Storz that chlamydia do in fact contain peptidoglycans, as the Gram-negative bacteria do.

PROF. T. BITTER: A small technical point. When lymphocytes are stimulated with an antigen there is a narrow critical range in antigen concentration. Too low a concentration will not stimulate, too high a concentration will inhibit the response.

PROF. AHO: We initially used antigens in different concentrations, and from the results of these tests we selected the concentrations that we used later on. DR. G. R. V. HUGHES: Did you have any cryoprecipates in serum or synovial fluids from your patients? PROF. AHO: Sera were very easy to obtain, since they are sent to our laboratory for various serological tests, but so far we have had very few synovial fluids. PROF. C. W. FINK: The rumour goes that somes patients with yersinia arthritis also developed disease similar to rheumatic fever with carditis and lesions of the heart valves.

PROF. AHO: Yes, these have been reported by Laitinen and co-workers. ${ }^{193}$ 